\title{
Opioid-use disorder among patients on long-term opioid therapy: impact of final DSM-5 diagnostic criteria on prevalence and correlates
}

This article was published in the following Dove Press journal:

Substance Abuse and Rehabilitation

19 August 2015

Number of times this article has been viewed

\author{
Joseph A Boscarino' \\ Stuart N Hoffman' \\ John J Han ${ }^{2}$ \\ 'Center for Health Research, \\ ${ }^{2}$ Department of Pain Medicine, \\ Geisinger Clinic, Danville, PA, USA
}

Correspondence: Joseph A Boscarino Geisinger Clinic, $100 \mathrm{~N}$ Academy Avenue, MC 44-00, Danville, PA I7822-4400, USA

$\mathrm{Tel}+\mathrm{I} 5702149622$

Fax + I 570214945

Email jaboscarino@geisinger.edu
Aims: Previously, we estimated the prevalence and risk factors for prescription opioid-use disorder among outpatients on opioid therapy using the Diagnostic and Statistical Manual of Mental Disorders (DSM)-5 and DSM-4 criteria. However, at the time, the DSM-5 criteria were not finalized. In the current study, we analyzed these data using the final DSM- 5 criteria and compared these results.

Methods: Using electronic records from a large US health care system, we identified outpatients receiving five or more prescription orders for opioid therapy in the past 12 months for noncancer pain (mean prescription orders $=10.72$; standard deviation $=4.96$ ). In 2008, we completed diagnostic interviews with 705 of these patients using the DSM-4 criteria. In the current study, we reassessed these results using the final DSM- 5 criteria.

Results: The lifetime prevalence of DSM-5 opioid-use disorders using the final DSM- 5 criteria was $58.7 \%$ for no or few symptoms $(<2), 28.1 \%$ for mild symptoms $(2-3), 9.7 \%$ for moderate symptoms (4-5), and $3.5 \%$ for severe symptoms (six or more). Thus, the lifetime prevalence of "any" prescription opioid-use disorder in this cohort was $41.3 \%$ ( $95 \%$ confidence interval $[\mathrm{CI}]=37.6-45.0$ ). A comparison to the DSM-4 criteria indicated that the majority of patients with lifetime DSM-4 opioid dependence were now classified as having mild opioid-use disorder, based on the DSM-5 criteria $(53.6 \%$; 95\% CI $=44.1-62.8)$. In ordinal logistic regression predicting no/few, mild, moderate, and severe opioid-use disorder, the best predictors were age $<65$ years, current pain impairment, trouble sleeping, suicidal thoughts, anxiety disorders, illicit drug use, and history of substance abuse treatment.

Conclusion: Given the final DSM-5 criteria, including the elimination of tolerance and withdrawal, inclusion of craving and abuse symptoms, and introduction of a new graded severity classification, the prevalence of opioid-use disorders has changed, while many of the DSM-4 risk factors for opioid dependence were similar. To our knowledge, this is one of the first studies to compare the final results for DSM-5 versus DSM-4 prescription opioid-use disorders among a high-risk patient population.

Keywords: opioids, drug-use disorders, DSM-5, prescription drugs, pain, outpatients

\section{Introduction}

The prevalence of prescription opioid drug abuse and drug dependence in the USA has increased in the past decade, representing a serious public health threat. ${ }^{1-4}$ The revised diagnostic criteria for the Diagnostic and Statistical Manual of Mental Disorders, Fifth Edition (DSM-5) included significant modifications for prescription opioid-use disorder. ${ }^{5}$ These changes included the exclusion of the tolerance and withdrawal symptoms for those taking opioids under appropriate medical supervision. ${ }^{6,7}$ The rationale for this was that these symptoms would be "iatrogenic", rather than psychopathogenic, 
in a therapeutic context. ${ }^{6,7}$ In addition, given the conceptual problems noted in DSM-4 between "abuse" and "dependence", it was recommended to combine these symptom clusters into a single disorder of graded severity. ${ }^{6,8}$ Previously, we compared the lifetime diagnostic results for the DSM-5 versus the DSM-4 for prescription opioid-use disorder, but this was based on the preliminary criteria proposed by the American Psychiatric Association (APA), not the final criteria. ${ }^{5,7}$ Given that the final APA classification was modified, the objectives of the current study are to assess the prevalence of DSM-5 prescription opioid-use disorder among a highrisk patient population based on the final DSM-5 criteria, to identify the correlates associated with this final classification, and to compare the final DSM-5 criteria results to those using the DSM-4 criteria. Given the final changes proposed by the APA for prescription opioid-use disorder, ${ }^{5}$ differences were expected.

\section{Methods}

\section{Sample}

As described elsewhere, ${ }^{4,7}$ the study subjects were randomly selected from primary and specialty care outpatients seen in the Geisinger Clinic, which is part of the Geisinger Health System (Danville, PA, USA), an integrated multihospital system that serves residents in 44 central and northeastern Pennsylvania counties. Patients were eligible for this study if they were 18 years of age or older, received care from one of nine community practice clinics or from three specialty clinics (including a pain, arthritis, and orthopedic clinic), and had five or more prescription opioid medication orders for nonmalignant pain in the electronic health record (EHR) in the past 12 months (mean prescription orders $=10.72$; standard deviation $[\mathrm{SD}]=4.96)$. Preliminary data analyses suggested that this cut-off point was associated with problematic drug use. It is noted that this count was based on the number of drug orders recorded in the EHR, not the actual number of prescriptions filled or refilled, which we did not have access to at the time. In the outpatient setting, opioids tend to be ordered by providers in small doses (ie, $<30$ pills) with no automatic refills prescribed. Consequently, numerous drug orders are seen in the EHR, but this does not mean that the average patient had $\sim 11$ months of exposure to opioid medications in the past 12 months.

\section{Data collection}

Telephone interviews for this study were completed from August 2007 through November 2008. Following patient notification letters, telephone recruitment was initiated.
A total of 2,373 patients were initially identified as eligible for the survey and they were contacted by telephone. Of these patients, 234 were determined to be ineligible due to death, institutionalization, language barriers, illness, denial of opioid use, or being in the last group (number [n] =79) not contacted due to survey completion. Our survey completion rate was $705 / 2,139=33 \%$, and our survey cooperation rate (ie, the percent interviewed after patient contact) was $51 \%(705 / 1,390) .{ }^{4,7}$

Following informed consent, structured diagnostic interviews were administered by telephone to assess depression, post-traumatic stress disorder (PTSD), general anxiety, and psychological trauma, ${ }^{9-11}$ as well as opioid dependence, ${ }^{12-14}$ tobacco dependence, ${ }^{15}$ and childhood adversity. ${ }^{16}$ We examined these domains because we wanted to determine the key factors that predict opioid disorders in clinical practice, as was done recently for PTSD. ${ }^{17}$ The survey was administered by trained interviewers using a computer-assisted telephone interviewing system located at Geisinger's Center for Health Research in Danville, PA, USA. This study was approved by the Geisinger Clinic's Institutional Review Board.

\section{Lifetime DSM-5 and DSM-4 opioid disorders}

For the present study, aberrant opioid use was defined based on both the DSM-4 criteria for dependence and the final DSM-5 criteria for opioid-use disorder published in 2013. ${ }^{5,18}$ Because we assessed prescription opioid use at the beginning of the interview, we used a scale adapted for phone administration that had been previously validated. ${ }^{14}$ The criteria for opioid dependence on this scale were concordant with DSM-4 nomenclature. ${ }^{18}$ Lifetime DSM-4 prescription opioid dependence was defined as the presence of three or more prescription opioid symptoms (eg, health, family, functional, or legal problems) in the patient's history. Consistent with the recently released DSM-5 criteria for prescription opioid-use disorder, ${ }^{5}$ however, we also counted the occurrence of opioid dependence symptoms, but excluded those for tolerance and withdrawal. In addition, we included one opioid-craving symptom and three prescription opioid abuse symptoms in this symptom count, but eliminated legal problems, as stipulated in the DSM-5. ${ }^{5}$ It is noted that the craving measure used was available for lifetime occurrence only. Thus, unlike our previous study, ${ }^{4}$ the current study is restricted to only lifetime opioid-use disorders. Typically, diagnostic interviews assess symptom counts for lifetime and for the past 12 months. ${ }^{9,12}$ Based on these symptom counts, the DSM-5 nomenclature also included a severity classification, whereby patients 
having no or few symptoms $(<2)$, mild symptoms $(2-3)$, moderate symptoms (4-5), and severe symptoms (six or more) were classified accordingly. In our previous DSM-5 comparison study, ${ }^{7}$ this classification system was not finalized at the time and only included three categories: no or few symptoms $(<2)$; moderate symptoms $(2-3)$; and severe symptoms (four or more), which was a study limitation.

\section{Other study measures}

Since our other study measures were discussed elsewhere, ${ }^{4,7}$ we will briefly review them here. Our study also included alcohol dependence and tobacco (nicotine) dependence. Alcohol dependence was assessed based on DSM-4 criteria using the Composite International Diagnostic Interview scale. ${ }^{12}$ The Fagerstrom Tolerance Scale (FTS) was used to assess nicotine dependence. ${ }^{15,19}$ The FTS has good concurrent and predictive validity for nicotine dependence and it has been widely used..$^{20}$ Major depression was assessed using a depression measure developed from the Structured Clinical Interview for DSM, ${ }^{11}$ and it was validated in other surveys. ${ }^{21-23}$ PTSD was based on the DSM-4, developed for telephone administration, and used in previous trauma studies. ${ }^{9,24,25} \mathrm{We}$ also used the Brief Pain Inventory to assess pain status, a widely used measure for chronic pain evaluation. ${ }^{26,27}$ Trauma exposure was assessed using a childhood adversity and a lifetime trauma scale, respectively. Childhood adversity was assessed using a validated scale. ${ }^{16,28,29}$ For trauma exposure, we used a measure that focused on the major lifetime traumatic events experienced (eg, forced sexual contact, being physically attacked, etc). This scale has been used and validated in previous studies. ${ }^{9,24,25}$ Other study measures included a history of substance abuse treatments, psychotropic medication use, illicit drug use (eg, methamphetamine, heroin, cocaine use, etc), and self-reported health status., ${ }^{4,7}$

\section{Statistical analyses}

With institutional review board approval, we analyzed selection bias using the EHR data to compare study respondents (total number $[\mathrm{N}]=705)$ to nonrespondents $(\mathrm{N}=1,434)$ by age, sex, and clinic type. We then used these results to develop case weights to adjust for possible selection bias. These weights corrected for the fact that women and specialty clinic patients tended to have higher survey response rates. Next, we examined the descriptive statistics for DSM-5 prescription opioid-use disorder by demographic and clinical risk factor characteristics (Tables 1 and 2). In these bivariate analyses, opioid-use disorder was dichotomized as moderate/ severe $(n=93)$ versus not moderate/severe $(n=612)$, based on the final APA criteria for the DSM-5. ${ }^{5}$ We also calculated point estimates for DSM-5 opioid-use disorder (with 95\% confidence intervals [CIs]) and compared these to DSM-4 opioid dependence (Table 3). Next, we completed an ordinal logistic regression to identify the key risk factors for DSM-5 opioid-use disorder (Table 4). To identify the best adjusted model, variables with bivariate $P$-values $<0.05$ were selected as covariates in these analyses. Variables that remained significant were retained in the final adjusted model. This adjusted regression model was used to assess risk factors for the severity of DSM-5 opioid-use disorder, classified as none/ few symptoms, mild symptoms, moderate symptoms, and severe symptoms, with "none/few" used as the reference category. ${ }^{30}$ Since these patients were clustered within clinics, we also used the survey module in Stata (version 13.1) to adjust for patient clustering in all analyses. ${ }^{31}$ Finally, it is noted that phone surveys produce similar results as in-person interviews. ${ }^{32-34}$ The advantages of phone surveys include cost, patient privacy, convenience, and coverage. The limitation of phone surveys is that researchers have to simplify some survey response options because visual aids are typically unavailable during these interviews. ${ }^{32}$ However, today, most diagnostic interviews and psychometric scales are available in both survey formats. ${ }^{21-24,32}$

\section{Results}

Nonresponse analyses suggested that nonparticipants tended to be male, not married, current smokers, seen in primary care clinics, and less physically ill than study participants $(P<0.05)$. However, no differences were found in participation rates by race, employment status, obesity level, or the number of prescription opioid orders received in the past 3 years. Based on these results, case weights were developed to adjust for differences in participation by sex and clinic setting, and these weights were used in all analyses.

As shown in Table 1, using the final DSM-5 criteria, $13.2 \%$ of patients $(95 \% \mathrm{CI}=9.8-17.6)$ were classified as having moderate to severe lifetime opioid-use disorder. However, most demographic and clinical measures assessed were not associated with this disorder. Two noteworthy exceptions were for age less than 65 years $(P<0.001)$ and for reporting fair/poor health status $(P<0.01)$. The other opioid-use disorder associations found for medical demographic measures were for nonwhite race, being seen in a specialty clinic, and reporting greater pain impairment $(P$-values $<0.05)$ (Table 1$)$. By comparison, opioid-use disorder was significantly associated with a number of mental health comorbidities, including alcohol dependence, 
Table I Demographic and health characteristics of patients meeting the DSM-5 criteria for lifetime prescription opioid-use disorder (moderate or severe ${ }^{\#}$ )

\begin{tabular}{|c|c|c|c|c|c|c|c|}
\hline \multirow[t]{2}{*}{ Study variables } & \multicolumn{3}{|c|}{ Total sample } & \multicolumn{2}{|c|}{$\begin{array}{l}\text { DSM-5 opioid-use } \\
\text { disorder } \\
\text { Moderate or } \\
\text { severe }\end{array}$} & \multicolumn{2}{|c|}{$\begin{array}{l}\text { DSM-5 opioid-use } \\
\text { disorder } \\
\text { Not moderate or } \\
\text { severe }\end{array}$} \\
\hline & $\mathbf{N}$ & Percent & $(95 \% \mathrm{Cl})$ & $\mathbf{N}$ & Percent & $\mathbf{N}$ & Percent \\
\hline \multicolumn{8}{|l|}{ DSM-5 opioid-use disorder } \\
\hline \multicolumn{8}{|l|}{ Moderate/severe } \\
\hline$\%$ no & 612 & 86.8 & $(82.4-90.2)$ & & & & \\
\hline$\%$ yes & 93 & 13.2 & $(9.8-17.6)$ & & & & \\
\hline \multicolumn{8}{|l|}{ Age } \\
\hline$\%$ 18-64 years old & 558 & 79.3 & $(66.7-88.0)$ & 90 & 16.1 & 468 & $83.9 * * *$ \\
\hline$\%$ 65+ years old & 147 & 20.7 & $(12.0-33.3)$ & 3 & 1.8 & 144 & 98.2 \\
\hline \multicolumn{8}{|l|}{ Sex } \\
\hline$\%$ male & 232 & 39.1 & $(34.3-44.1)$ & 36 & 14.9 & 196 & 85.1 \\
\hline$\%$ female & 473 & 60.9 & $(55.9-65.7)$ & 57 & 12.1 & 416 & 87.9 \\
\hline \multicolumn{8}{|l|}{ Race } \\
\hline$\%$ white & 694 & 98.4 & (95.4-99.5) & 90 & 12.8 & 604 & $87.2^{*}$ \\
\hline$\%$ nonwhite & 11 & 1.6 & $(0.5-4.7)$ & 3 & 34.2 & 8 & 65.8 \\
\hline \multicolumn{8}{|l|}{ Marital status } \\
\hline$\%$ married & 458 & 65.6 & $(61.8-69.2)$ & 58 & 12.8 & 400 & 87.2 \\
\hline$\%$ not married & 247 & 34.4 & $(30.8-38.2)$ & 35 & 14.0 & 212 & 86.0 \\
\hline \multicolumn{8}{|l|}{ Employment status } \\
\hline \% employed & 179 & 25.7 & $(22.1-29.6)$ & 19 & 11.9 & 160 & 89.1 \\
\hline$\%$ not employed & 526 & 74.3 & (70.4-77.9) & 74 & 14.0 & 452 & 86.0 \\
\hline \multicolumn{8}{|l|}{ Household income } \\
\hline$\%$ less than US $\$ 30,000$ per year & 289 & 41.0 & $(33.0-49.5)$ & 43 & 14.6 & 246 & 85.4 \\
\hline$\%$ greater than US $\$ 30,000$ per year & 326 & 46.3 & $(40.8-52.1)$ & 41 & 12.8 & 285 & 87.2 \\
\hline$\%$ refused $/$ not reported & 90 & 12.7 & $(8.6-18.3)$ & 9 & 10.2 & 81 & 89.9 \\
\hline \multicolumn{8}{|l|}{ Education } \\
\hline$\%$ high school or less & 351 & 50.2 & $(46.1-54.3)$ & $4 I$ & 11.7 & 310 & 88.3 \\
\hline \% some college or more & 352 & 49.8 & $(45.7-53.9)$ & 52 & 14.7 & 300 & 85.3 \\
\hline \multicolumn{8}{|l|}{ Clinic setting } \\
\hline$\%$ primary care & 563 & 83.1 & $(47.1-96.5)$ & 68 & 12.2 & 495 & $87.8^{*}$ \\
\hline$\%$ specialty care & 142 & 16.9 & $(3.5-52.9)$ & 25 & 18.1 & 117 & 81.9 \\
\hline \multicolumn{8}{|l|}{ Reported health status } \\
\hline$\%$ good & 570 & 80.8 & $(76.2-84.7)$ & 61 & 10.7 & 509 & $89.3 * *$ \\
\hline$\%$ fair/poor & 135 & 19.2 & $(15.4-23.8)$ & 32 & 23.6 & 103 & 76.4 \\
\hline \multicolumn{8}{|l|}{ Medically obese (BMI >30) } \\
\hline$\%$ yes & 353 & 50.3 & $(45.3-55.2)$ & 49 & 13.6 & 304 & 86.4 \\
\hline$\%$ no & 352 & 49.7 & $(44.8-54.7)$ & 44 & 12.8 & 308 & 87.2 \\
\hline \multicolumn{8}{|l|}{ Reported average pain in past week } \\
\hline$\%$ high & 173 & 23.8 & $(18.4-30.2)$ & 31 & 17.8 & 142 & 82.2 \\
\hline$\%$ not high & 532 & 76.2 & $(69.8-81.6)$ & 62 & 11.7 & 470 & 88.3 \\
\hline \multirow{2}{*}{\multicolumn{8}{|c|}{$\begin{array}{l}\text { Reported pain interference with life or } \\
\text { work - greatly or extremely }\end{array}$}} \\
\hline & & & & & & & \\
\hline$\%$ yes & 426 & 60.4 & $(55.4-65.1)$ & 70 & 16.5 & 356 & $83.5^{*}$ \\
\hline$\%$ no & 279 & 39.6 & $(34.9-44.6)$ & 23 & 8.2 & 256 & 91.8 \\
\hline$(\mathrm{N})$ & $(705)$ & & & (93) & & $(6 \mid 2)$ & \\
\hline
\end{tabular}

Notes: \#All percent results were adjusted/weighted for response bias and data clustering; Ns are unweighted. by column and the disorder severity columns are percentized by row. $* P<0.05 ; * * P<0.01$; and $* * * P<0.001$.

Abbreviations: DSM-5, Diagnostic and Statistical Manual of Mental Disorders, Fifth Edition; N, number; Cl, confidence interval; BMI, body mass index.

major depression, generalized anxiety disorder, PTSD, childhood adversity, psychological trauma, illicit drug use, substance abuse treatment, psychotropic medication use, history of antisocial personality disorder, and other measures of psychological disturbance $(P$-values $<0.01)$ (Table 2). We then cross-tabulated the results for patients based on the final DSM-5 versus the DSM-4 nomenclature, and these results are shown in Table 3. As seen, the majority of patients are now classified as having no or few symptoms (58.7\%) and approximately one-third (28.1\%) are classified as having mild symptoms. By comparison, only $13.2 \%(9.7 \%+3.5 \%=13.2 \%)$ are classified as having moderate to severe symptoms (Table 3). This DSM-5 classification appears to represent a departure from 
Table 2 Mental health characteristics of patients meeting the DSM-5 criteria for lifetime prescription opioid-use disorder (moderate or severe ${ }^{\#}$ )

\begin{tabular}{|c|c|c|c|c|c|c|c|}
\hline \multirow[t]{2}{*}{ Study variables } & \multicolumn{3}{|c|}{ Total sample } & \multicolumn{2}{|c|}{$\begin{array}{l}\text { DSM-5 opioid-use } \\
\text { disorder } \\
\text { Moderate or } \\
\text { severe }\end{array}$} & \multicolumn{2}{|c|}{$\begin{array}{l}\text { DSM-5 opioid-use } \\
\text { disorder } \\
\text { Not moderate or } \\
\text { severe }\end{array}$} \\
\hline & $\mathbf{N}$ & Percent & $(95 \% \mathrm{Cl})$ & $\mathbf{N}$ & Percent & $\mathbf{N}$ & Percent \\
\hline \multicolumn{8}{|c|}{ Lifetime alcohol dependence } \\
\hline$\%$ yes & 68 & 9.8 & $(7.1-13.3)$ & 23 & 32.6 & 45 & $67.4 * *$ \\
\hline$\%$ no & 637 & 90.2 & $(86.7-92.9)$ & 70 & II.I & 567 & 88.9 \\
\hline \multicolumn{8}{|c|}{ Lifetime tobacco dependence } \\
\hline$\%$ yes & 251 & 36.8 & $(32 . I-4 I .9)$ & 42 & 16.8 & 209 & $83.2^{*}$ \\
\hline$\%$ no & 454 & 63.2 & $(58.2-68.0)$ & 51 & II.I & 403 & 88.9 \\
\hline \multicolumn{8}{|c|}{ Lifetime major depressive disorder } \\
\hline$\%$ yes & 249 & 34.6 & $(29.8-39.7)$ & 63 & 25.8 & 186 & $74.2^{* * *}$ \\
\hline$\%$ no & 456 & 65.4 & $(60.3-70.2)$ & 30 & 6.5 & 426 & 93.5 \\
\hline \multicolumn{8}{|c|}{ Lifetime generalized anxiety disorder } \\
\hline$\%$ yes & 89 & 12.6 & $(|0.0-| 5.8)$ & 26 & 30.1 & 63 & $69.9^{* * *}$ \\
\hline$\%$ no & 616 & 87.4 & $(84.2-90.1)$ & 67 & 10.8 & 549 & 89.2 \\
\hline \multicolumn{8}{|c|}{ Lifetime post-traumatic stress disorder } \\
\hline$\%$ yes & 97 & 13.3 & $(10.1-17.3)$ & 29 & 30.6 & 68 & $69.4^{* * *}$ \\
\hline$\%$ no & 608 & 86.7 & $(82.7-90.0)$ & 64 & 10.5 & 544 & 89.5 \\
\hline \multicolumn{8}{|c|}{ History of high childhood adversity } \\
\hline$\%$ yes & 178 & 24.9 & $(21.3-28.8)$ & 40 & 22.7 & 138 & $77.3^{* * *}$ \\
\hline$\%$ no & 527 & 75.1 & (7I.2-78.7) & 53 & 10.0 & 474 & 90.0 \\
\hline \multicolumn{8}{|c|}{ History of high exposure to psychological trauma } \\
\hline$\%$ yes & 161 & 23.0 & $(19.0-27.5)$ & 41 & 24.6 & 120 & $75.4^{* * *}$ \\
\hline$\%$ no & 544 & 77.0 & $(72.5-81.0)$ & 52 & 9.8 & 492 & 90.2 \\
\hline \multicolumn{8}{|c|}{ History of illicit drug use } \\
\hline$\%$ yes & 167 & 24.1 & $(21.5-26.8)$ & 39 & 22.7 & 128 & $77.3^{* * *}$ \\
\hline$\%$ no & 432 & 75.9 & $(73.2-78.5)$ & 54 & 10.2 & 484 & 89.8 \\
\hline \multicolumn{8}{|c|}{ History of any substance abuse treatment } \\
\hline$\%$ yes & 153 & 22.5 & $(20.3-25.0)$ & 49 & 31.3 & 104 & $68.7^{* * *}$ \\
\hline$\%$ no & 552 & 77.5 & $(75.0-79.1)$ & 44 & 7.9 & 508 & 92.1 \\
\hline \multicolumn{8}{|c|}{ Current psychotropic medication use } \\
\hline$\%$ yes & 434 & 61.1 & $(58.2-64.0)$ & 81 & 18.7 & 353 & $81.3^{* * *}$ \\
\hline$\%$ no & 271 & 38.9 & $(36.0-41.8)$ & 12 & 4.5 & 259 & 95.5 \\
\hline \multicolumn{8}{|c|}{ Antisocial personality disorder } \\
\hline$\%$ yes & 167 & 23.8 & $(21.6-26.1)$ & 40 & 23.3 & 127 & $76.7^{* *}$ \\
\hline$\%$ no & 538 & 76.2 & (73.9-78.4) & 53 & 10.0 & 485 & 90.0 \\
\hline \multicolumn{8}{|c|}{ Ever sleeping problems } \\
\hline$\%$ yes & 461 & 64.4 & $(58.6-69.9)$ & 83 & 18.1 & 378 & $81.9 * * *$ \\
\hline$\%$ no & 244 & 35.6 & $(30.1-4 I .4)$ & 10 & 4.3 & 234 & 95.7 \\
\hline \multicolumn{8}{|c|}{ Ever suicidal thoughts } \\
\hline$\%$ yes & 182 & 25.6 & $(22.2-29.4)$ & 52 & 29.0 & 130 & $71.0^{* * *}$ \\
\hline$\%$ no & 523 & 74.4 & $(70.6-77.8)$ & 41 & 7.7 & 482 & 92.3 \\
\hline$(\mathrm{N})$ & (705) & & & $(93)$ & & $(6 \mid 2)$ & \\
\hline
\end{tabular}

Notes: ${ }^{\# A l l ~ p e r c e n t ~ r e s u l t s ~ w e r e ~ a d j u s t e d / w e i g h t e d ~ f o r ~ r e s p o n s e ~ b i a s ~ a n d ~ d a t a ~ c l u s t e r i n g ; ~ N s ~ a r e ~ u n w e i g h t e d . ~}{ }^{\#}$ To aid in data interpretation, the total column is percentized by column and the disorder severity columns are percentized by row. $* P<0.05 ; * * P<0.01$; and $* * * P<0.00 \mathrm{I}$.

Abbreviations: DSM-5, Diagnostic and Statistical Manual of Mental Disorders, Fifth Edition; N, number; Cl, confidence interval.

both the DSM-4 and the tentative DSM- 5 criteria proposed by the APA in 2011.

Next, based on these bivariate results, a multivariate model was developed for the DSM-5 opioid-use disorder. Using the selection criteria discussed, eight predictor variables were identified for inclusion in the final model. Since the DSM-5 opioid-use disorder severity classifications include the presence of no/few symptoms, mild symptoms, moderate symptoms, and severe symptoms, we used ordinal logistic regression to examine these outcomes (Table 4). As can be seen, the best predictors of higher opioid-use disorder severity include age less than 65 years, pain interference, trouble sleeping, suicidal thoughts, generalized anxiety, illicit drug use, and a history of substance abuse treatment ( $P$-values $<0.05)$. Among these variables, pain, trouble sleeping, suicidal thoughts, and substance abuse treatment are the 
Table 3 Prevalence of lifetime DSM-5 prescription opioid-use disorder by lifetime DSM-4 prescription opioid dependence ${ }^{\#}$

\begin{tabular}{|c|c|c|c|c|c|c|c|c|c|c|c|c|}
\hline \multirow[t]{2}{*}{ Diagnostic criteria* } & \multicolumn{3}{|c|}{$\begin{array}{l}\text { DSM-5 opioid-use } \\
\text { disorder: none/low } \\
\text { (<2 symptoms) }\end{array}$} & \multicolumn{3}{|c|}{$\begin{array}{l}\text { DSM-5 opioid-use } \\
\text { disorder: mild } \\
\text { (2-3 symptoms) }\end{array}$} & \multicolumn{3}{|c|}{$\begin{array}{l}\text { DSM-5 opioid-use } \\
\text { disorder: moderate } \\
\text { (4-5 symptoms) }\end{array}$} & \multicolumn{3}{|c|}{$\begin{array}{l}\text { DSM-5 opioid-use } \\
\text { disorder: severe } \\
\text { (6+ symptoms) }\end{array}$} \\
\hline & $\%$ & $95 \% \mathrm{Cl}$ & (n) & $\%$ & $95 \% \mathrm{Cl}$ & (n) & $\%$ & $95 \% \mathrm{Cl}$ & (n) & $\%$ & $95 \% \mathrm{Cl}$ & (n) \\
\hline $\begin{array}{l}\text { DSM-4 no opioid } \\
\text { dependence }\end{array}$ & 86.0 & $82.2-89.1$ & (391) & 14.0 & $11.0-17.8$ & $(63)$ & 0.0 & - & $(0)$ & 0.0 & - & $(0)$ \\
\hline DSM-4 opioid dependence & 9.3 & $5.8-14.6$ & (23) & 53.6 & $44.1-62.8$ & $(135)$ & 27.3 & $22.1-33.1$ & (69) & 9.8 & $6.7-14.3$ & (24) \\
\hline $\begin{array}{l}\text { Total DSM-5 opioid-use } \\
\text { disorder }\end{array}$ & 58.7 & $54.2-63.1$ & $(4 \mid 4)$ & 28.1 & $25.4-30.9$ & (198) & 9.7 & $7.3-12.8$ & (69) & 3.5 & $2.2-5.5$ & (24) \\
\hline
\end{tabular}

Notes: ${ }^{\# A l l ~ p e r c e n t ~ r e s u l t s ~ a r e ~ a d j u s t e d / w e i g h t e d ~ f o r ~ r e s p o n s e ~ b i a s ~ a n d ~ d a t a ~ c l u s t e r i n g ; ~ n s ~ a r e ~ u n w e i g h t e d . ~} * \mathrm{P}<0.000$ I.

Abbreviations: DSM-5, Diagnostic and Statistical Manual of Mental Disorders, Fifth Edition; DSM-4, Diagnostic and Statistical Manual of Mental Disorders, Fourth Edition; $\mathrm{Cl}$, confidence interval; $\mathrm{n}$, number.

most significant predictors of lifetime DSM-5 opioid-use disorder severity $(P$-values $<0.01)$.

\section{Discussion}

Based on the preliminary DSM-5 criteria available at the time, our earlier study suggests that $35 \%(95 \% \mathrm{CI}=30.5-39.5)$ of the patients on long-term opioid therapy met the criteria for lifetime prescription opioid-use disorder. ${ }^{7}$ This was approximately the same percent that met the DSM- 4 criteria for opioid dependence. The kappa coefficient for those meeting these preliminary DSM-5 and final DSM- 4 criteria in our earlier study was high (kappa $=0.873 ; P<0.0001$ ), suggesting considerable overlap. ${ }^{7}$ This finding was surprising at the time, given the changes proposed in the DSM-5. As was seen in the current study, this does not appear to be the case using the final severity classifications issued by the APA in 2013, which included having no/few symptoms $(<2)$, mild symptoms (2-3), moderate symptoms (4-5), and severe symptoms $(\geq 6) .{ }^{5}$ Thus, under the final APA nomenclature,

Table 4 Ordinal logistic regression model predicting lifetime DSM-5 opioid-use disorders $(\mathrm{N}=705)^{\#}$

\begin{tabular}{llll}
\hline Predictor variables & OR & $\mathbf{9 5 \%} \mathbf{C I}$ & P-value \\
\hline Less than 65 years old & $\mathrm{I} .86$ & $\mathrm{I} .14-3.04$ & 0.013 \\
Pain interferes with work/life & $2.0 \mathrm{I}$ & $\mathrm{I} .38-2.93$ & $<0.00 \mathrm{I}$ \\
Ever trouble sleeping & $\mathrm{I} .8 \mathrm{I}$ & $\mathrm{I} .28-2.55$ & $0.00 \mathrm{I}$ \\
Ever suicidal thoughts & $\mathrm{I} .65$ & $\mathrm{I} .29-2.12$ & $<0.00 \mathrm{I}$ \\
History of general anxiety & $\mathrm{I} .63$ & $\mathrm{I} . \mathrm{II}-2.38$ & 0.013 \\
History of post-traumatic stress disorder & $\mathrm{I} .40$ & $0.99-2.00$ & 0.058 \\
History of illicit drug use & $\mathrm{I} .75$ & $\mathrm{I} .10-2.78$ & 0.018 \\
Ever substance abuse treatment & 2.28 & $\mathrm{I} .59-3.26$ & $<0.00 \mathrm{I}$ \\
Cut I & 2.23 & $\mathrm{I} .66-2.8 \mathrm{I}$ & - \\
Cut 2 & 4.05 & $3.43-4.68$ & - \\
Cut 3 & 5.66 & $4.89-6.42$ & - \\
\hline
\end{tabular}

Notes: \#All of the results are adjusted/weighted for survey response bias and data clustering. Ordinal contrasts include no opioid-use disorder $(n=4 \mid 4)$, mild opioiduse disorder $(n=198)$, moderate opioid-use disorder $(n=69)$, and severe opioid-use disorder $(n=24)$. Cuts I-3 represent the coefficients used to estimate an ordinal model with 4 categories, representing no disorder, mild, moderate, and severe disorder.

Abbreviations: DSM-5, Diagnostic and Statistical Manual of Mental Disorders, Fifth Edition; $\mathrm{N}$, total number; $\mathrm{OR}$, odds ratio; $\mathrm{Cl}$, confidence interval; $\mathrm{n}$, sample number. only $13.2 \%$ of patients meet the criteria for moderate to severe opioid-use disorder, which is the subgroup that would likely be of highest risk for addiction. However, $41.3 \%$ (95\% CI $=37.6-45.0$ ) of patients now met the criteria for having any lifetime prescription opioid-use disorder.

In the bivariate analyses, being younger and reporting a poorer health status were significantly associated with DSM-5 opioid-use disorder severity (Table 1), as was alcohol dependence, tobacco dependence, major depression, generalized anxiety disorder, a history of childhood adversity, exposure to psychological trauma, illicit drug use, substance abuse treatment, psychotropic medication use, a history of antisocial personality, sleep disturbance, and suicidal thoughts (Table 2). Noteworthy is that these are mostly the same risk factors that were previously reported for DSM-4 opioid dependence. ${ }^{4,35}$

In the multivariate analysis using ordinal logistic regression to predict opioid-use disorder severity (ie, no/ few, mild, moderate, or severe symptoms), significant risk factors included younger age, pain impairment, sleeping problems, suicidal thoughts, generalized anxiety, illicit drug use, and a history of substance abuse treatment (Table 4). It was noted that these multivariate risk factors for prescription opioid-use disorder are similar to those reported for DSM-4 opioid dependence, with the exception of a history of drug abuse and severity of addiction, both of which are now explicitly included in the DSM-5 and therefore were not assessed in the current study. ${ }^{7}$ Given the scope of the changes proposed for the DSM-5, these outcomes were not expected.

This study has its strengths and limitations. The study strengths include that this research was based on a random sample of outpatients seen in a large multispecialty group practice; that drug-use disorder was assessed based on the final DSM-5 criteria; and that subjects were identified through drug orders in the EHR, not based on patient self-report or treatment records. Study limitations include the following: 
that our survey data were based on patient self-report; our survey completion rate was less than optimal; our current study only included lifetime opioid-use disorder; our drugcraving measure was limited; and our patients were drawn from a predominately Caucasian population in one US region. In addition to our low response rate, males were also underrepresented, as were nonwhite patients, all of which could have further skewed our results and may have affected the representativeness and validity of our study. As is common is survey research, however, we did use survey weights to adjust the data for potential response bias. ${ }^{9-11}$

To our knowledge, this is one of the few studies to compare the final DSM-5 criteria to DSM-4 for prescription opioids and to report the results for DSM-5 moderate and severe opioid-use disorders. ${ }^{36}$ We did not expect the prevalence of the DSM-5 disorders to vary significantly because our previous study used the criteria initially proposed by the APA in 2011 and found little variation. ${ }^{7}$ As shown in Table 3, however, there is more disparity than previously reported due to the changes in the final APA severity classifications. Nevertheless, the current findings appear to be consistent with recently reported observations. ${ }^{36}$ The DSM-4 prevalence estimates we reported in 2010 appeared to be higher than those typically reported in the literature at the time. ${ }^{4,37}$ As was shown, the lifetime prevalence of DSM-5 opioid-use disorders using the final DSM criteria was $28.1 \%$ for mild symptoms, $9.7 \%$ for moderate symptoms, and $3.5 \%$ for severe symptoms, suggesting that $41.3 \%$ of the patients had some symptoms (among those with more than one symptom), and $13.2 \%$ had moderate to severe symptoms. As we have noted, the prevalence of prescription opioid abuse in the USA has increased in the past decade, representing a major public health problem. ${ }^{1-3}$ Our objective is to replicate these findings and to investigate key correlates of the DSM-5 criteria in the future. ${ }^{4,35}$ Given that the DSM-5 addiction criteria were developed with a greater focus on the existing empirical evidence rather than on clinical consensus, ${ }^{6,38}$ perhaps we will be more likely to discover robust correlates of these disorders, ${ }^{39}$ which was a rationale for the DSM diagnostic nomenclature. ${ }^{40}$ We now know that most psychiatric disorders are inherently complex and represent a multitude of genetic and environmental risk factors. ${ }^{41}$ Given the refinement of the diagnostic criteria under the DSM-5, this discovery process might be more fruitful. As discussed, these changes included the elimination of the tolerance and withdrawal symptoms for those taking opioids under medical supervision, the elimination of legal problems, and the inclusion of abuse, dependence, and craving symptoms, all combined now into a single disorder of graded severity.

\section{Conclusion}

From a public health policy view, misuse and abuse of prescription opioids in the USA has increased significantly. ${ }^{42}$ However, it has been noted recently that opioid dispensing and prescription opioid overdoses have actually decreased in the USA following major changes in the pharmaceutical market in late $2010 .{ }^{43}$ This included the introduction of abuse-deterrent extended-release oxycodone hydrochloride and the withdrawal of propoxyphene. ${ }^{43}$ These two pharmaceutical market interventions appear to have reduced the prescription opioid overdoses, but heroin use rates have continued to increase..$^{3,43}$ The latter points to the complexity of contemporary addictionrelated disorders. ${ }^{44,45}$ Opioid therapy for noncancer pain is still commonplace today, despite the lack of clinical evidence as to its benefit. ${ }^{2,46}$ Previously, we developed a "risk-score" method to identify patients at risk for PTSD that included genetic risk information. ${ }^{47}$ In the future, it might be possible to use data routinely collected in the EHR, together with the other pertinent patient information, to identify patients at highest risk for opioid abuse. ${ }^{48}$ We think that the recently developed DSM-5 nomenclature for prescription opioid-use disorders could aid in this clinical endeavor.

\section{Acknowledgments}

Funding for this study was, in part, from a grant from the Administrative Committee for Research (ACR), Geisinger Clinic, grant number TRA-015 (Boscarino, principal investigator), and from the National Institute of Mental Health, grant number R21-MH-086317 (Boscarino, principal investigator). The study funders had no role in the study design, data collection, analysis, interpretation, writing, or in the decision to submit the manuscript for publication.

Preliminary results from this study were presented at the Annual HMO Research Network Conference, Danville, PA, April 2009, and at the NIDA/NIAAA Satellite Meeting on the Genetics and Epigenetics of Substance Abuse, World Congress on Psychiatric Genetics, Washington, DC, September 9, 2011.

\section{Disclosure}

The authors report no conflicts of interest in this work.

\section{References}

1. Manchikanti L, Fellows B, Ailinani H, Pampati V. Therapeutic use, abuse, and nonmedical use of opioids: a ten-year perspective. Pain Physician 2010;13(5):401-435.

2. Von Korff M, Kolodny A, Deyo RA, Chou R. Long-term opioid therapy reconsidered. Ann Intern Med. 2011;155(5):325-328.

3. Kuehn BM. SAMHSA: Pain medication abuse a common path to heroin: experts say this pattern likely driving heroin resurgence. JAMA. 2013; 310(14):1433-1434. 
4. Boscarino JA, Rukstalis M, Hoffman SN, et al. Risk factors for drug dependence among out-patients on opioid therapy in a large US healthcare system. Addiction. 2010;105(10):1776-1782.

5. American Psychiatric Association. Diagnostic and Statistical Manual of Mental Disorders. 5th ed. Arlington, DC: American Psychiatric Association; 2013.

6. Hasin DS, O'Brien CP, Auriacombe M, et al. DSM-5 criteria for substance use disorders: recommendations and rationale. Am J Psychiatry. 2013;170(8):834-851.

7. Boscarino JA, Rukstalis MR, Hoffman SN, et al. Prevalence of prescription opioid-use disorder among chronic pain patients: comparison of the DSM-5 vs DSM-4 diagnostic criteria. J Addict Dis. 2011;30(3): 185-194.

8. Saha TD, Compton WM, Chou SP, et al. Analyses related to the development of DSM-5 criteria for substance use related disorders: 1 . Toward amphetamine, cocaine and prescription drug use disorder continua using Item Response Theory. Drug Alcohol Depend. 2012; 122(1-2):38-46.

9. Boscarino JA, Adams RE. PTSD onset and course following the World Trade Center disaster: findings and implications for future research. Soc Psychiatry Psychiatr Epidemiol. 2009;44(10):887-898.

10. Adams RE, Boscarino JA, Galea S. Social and psychological resources and health outcomes after the World Trade Center disaster. Soc Sci Med. 2006;62(1):176-188.

11. Boscarino JA, Adams RE, Figley CR. Mental health service use 1-year after the World Trade Center disaster: implications for mental health care. Gen Hosp Psychiatry. 2004;26(5):346-358.

12. Kessler RC, Ustün TB. The World Mental Health (WMH) survey initiative version of the World Health Organization (WHO) Composite Internal Diagnostic Interview (CIDI). Int $J$ Methods Psychiatr Res. 2004;13(2):93-121.

13. Gossop M, Darke S, Griffiths P, et al. The Severity of Dependence Scale (SDS): psychometric properties of the SDS in English and Australian samples of heroin, cocaine and amphetamine users. Addiction. 1995; 90(5):607-614.

14. Kilpatrick DG, Ruggiero KJ, Acierno R, Saunders BE, Resnick HS, Best CL. Violence and risk of PTSD, major depression, substance abuse/dependence, and comorbidity: results from the National Survey of Adolescents. J Consult Clin Psychol. 2003;71(4):692-700.

15. Fagerström KO. Measuring degree of physical dependence to tobacco smoking with reference to individualization of treatment. Addict Behav. 1978;3(3-4):235-241.

16. Chapman DP, Whitfield CL, Felitti VJ, Dube SR, Edwards VJ, Anda RF. Adverse childhood experiences and the risk of depressive disorders in adulthood. J Affect Disord. 2004;82(2):217-225.

17. Boscarino JA, Kirchner HL, Hoffman SN, Sartorius J, Adams RE, Figley CR. The New York PTSD risk score for assessment of psychological trauma: male and female versions. Psychiatry Res. 2012; 200(2-3):827-834.

18. American Psychiatric Association. Diagnostic and Statistical Manual of Mental Disorders, Fourth Text Revision. Arlington, VA: American Psychiatric Publishing; 2000.

19. Heatherton TF, Kozlowski LT, Frecker RC, Fagerström KO. The Fagerström Test for Nicotine Dependence: a revision of the Fagerström Tolerance Questionnaire. Br J Addict. 1991;86(9):1119-1127.

20. Fagerstrom KO, Schneider NG. Measuring nicotine dependence: a review of the Fagerstrom Tolerance Questionnaire. J Behav Med. 1989;12(2):159-182.

21. Boscarino JA, Galea S, Adams RE, Ahern J, Resnick H, Vlahov D. Mental health service and medication use in New York City after the September 11, 2001, terrorist attack. Psychiatr Serv. 2004;55(3): 274-283.

22. Boscarino JA, Adams RE, Figley CR. Mental health service use after the World Trade Center disaster: utilization trends and comparative effectiveness. J Nerv Ment Dis. 2011;199(2):91-99.
23. Boscarino JA, Hoffman SN, Adams RE, Figley CR, Solhkhah R. Mental health outcomes among vulnerable residents after Hurricane Sandy: implications for disaster research and planning. Am J Disaster Med. 2014;9(2):107-120.

24. Galea S, Ahern J, Resnick H, et al. Psychological sequelae of the September 11 terrorist attacks in New York City. $N$ Engl J Med. 2002;346(13):982-987.

25. Adams RE, Boscarino JA. A structural equation model of perievent panic and posttraumatic stress disorder after a community disaster. J Trauma Stress. 2011;24(1):61-69.

26. Tan G, Jensen MP, Thornby JI, Shanti BF. Validation of the Brief Pain Inventory for chronic nonmalignant pain. J Pain. 2004;5(2): 133-137.

27. Cleeland CS, Ryan KM. Pain assessment: global use of the Brief Pain Inventory. Ann Acad Med Singapore. 1994;23(2):129-138.

28. Felitti VJ, Anda RF, Nordenberg D, et al. Relationship of childhood abuse and household dysfunction to many of the leading causes of death in adults. The Adverse Childhood Experiences (ACE) Study. Am J Prev Med. 1998;14(4):245-258.

29. Flaherty EG, Thompson R, Litrownik AJ, et al. Effect of early childhood adversity on child health. Arch Pediatr Adolesc Med. 2006;160(12):1232-1238

30. Long JS, Freese J. Regression Models for Categorical Dependent Variables Using SATA. 3rd ed. College Station, TX: Stata Press; 2014.

31. Stata Corporation. Stata statistical software, version 13.1. College Station, TX: StatCorp LP; 2013.

32. Groves RM, Folwer FJ Jr, Couper MP, Lepkowski JM, Singer E, Tourangeau R. Survey Methodology. 2nd ed. New York, NY: Wiley; 2009.

33. Paulsen AS, Crowe RR, Noyes R, Pfohl B. Reliability of the telephone interview in diagnosing anxiety disorders. Arch Gen Psychiatry. 1988;45(1):62-63.

34. Weeks MF, Kulka RA, Lessler JT, Whitmore RW. Personal versus telephone surveys for collecting household health data at the local level. Am J Public Health. 1983;73(12):1389-1394.

35. Erlich PM, Hoffman SN, Rukstalis M, et al. Nicotinic acetylcholine receptor genes on chromosome $15 \mathrm{q} 25.1$ are associated with nicotine and opioid dependence severity. Hum Genet. 2010;128(5):491-499.

36. Goldstein RB, Chou SP, Smith SM, et al. Nosologic comparisons of DSM-IV and DSM-5 alcohol and drug use disorders: results from the National Epidemiologic Survey on Alcohol and Related Conditions-III. J Stud Alcohol Drugs. 2015;76(3):378-388

37. Von Korff M. Commentary on Boscarino et al. (2010): understanding the spectrum of opioid abuse, misuse and harms among chronic opioid therapy patients. Addiction. 2010;105(10):1783-1784.

38. Hasin DS, Fenton MC, Beseler C, Park JY, Wall MM. Analyses related to the development of DSM-5 criteria for substance use related disorders: 2. Proposed DSM-5 criteria for alcohol, cannabis, cocaine and heroin disorders in 663 substance abuse patients. Drug Alcohol Depend. 2012;122(1-2):28-37.

39. Saunders JB, Schuckit MA, Sirovatka PJ, Regier DA, editors. Diagnostic Issues in Substance Use Disorders: Refining the Research Agenda for DSM-5. Arlington, VA: American Psychiatric Association; 2007.

40. Regier DA, Narrow WE, Kuhl EA, Kupfer DJ. The conceptual development of DSM-V. Am J Psychiatry. 2009;166(6):645-650.

41. Gelernter J. Genetics of complex traits in psychiatry. Biol Psychiatry. 2015;77(1):36-42.

42. Dart RC, Surratt HL, Cicero TJ, et al. Trends in opioid analgesic abuse and mortality in the United States. N Engl J Med. 2015;372(3):241-248.

43. Larochelle MR, Zhang F, Ross-Degnan D, Wharam JF. Rates of opioid dispensing and overdose after introduction of abuse-deterrent extendedrelease oxycodone and withdrawal of propoxyphene. JAMA Intern Med. 2015;175(6):978-987.

44. O'Brien CP, Volkow N, Li TK. What's in a word? Addiction versus dependence in DSM-V. Am J Psychiatry. 2006;163(5):764-765. 
45. Martell BA, O'Connor PG, Kerns RD, et al. Systematic review: opioid treatment for chronic back pain: prevalence, efficacy, and association with addiction. Ann Intern Med. 2007;146(2):116-127.

46. Von Korff M, Korff MV, Saunders K, et al. De facto long-term opioid therapy for noncancer pain. Clin J Pain. 2008;24(6):521-527.
47. Boscarino JA, Kirchner HL, Hoffman SN, Erlich PM. Predicting PTSD using the New York Risk Score with genotype data: potential clinical and research opportunities. Neuropsychiatr Dis Treat. 2013;9:517-527.

48. Cheatle MD, Barker C. Improving opioid prescription practices and reducing patient risk in the primary care setting. J Pain Res. 2014;7:301-311.

Substance Abuse and Rehabilitation

\section{Publish your work in this journal}

Substance Abuse and Rehabilitation is an international, peer-reviewed, open access journal publishing original research, case reports, editorials, reviews and commentaries on all areas of addiction and substance abuse and options for treatment and rehabilitation. The manuscript management system is completely online and includes a very quick and fair peer-review system. Visit http://www.dovepress.com/testimonials.php to read real quotes from published authors.

\footnotetext{
Submit your manuscript here: http://www.dovepress.com/substance abuse-and-rehabilitation-journal
} 